\title{
The effect of surface mechanical attrition treatment on low temperature plasma nitriding of an austenitic stainless steel
}

\author{
M. Chemkhi ${ }^{1}$, D. Retraint ${ }^{1,}$, A. Roos ${ }^{1}$, C. Garnier ${ }^{1}$, L. Waltz ${ }^{2}$, C. Demangel ${ }^{3}$, G. \\ Proust $^{4}$ \\ ${ }^{1}$ University of Technology of Troyes (UTT), Charles Delaunay Institute, LASMIS, UMR STMR CNRS \\ 6279, 12 rue Marie Curie, 10000 Troyes, France \\ ${ }^{2}$ Laboratoire de Mécanique et Génie Civil (LMGC) de Montpellier 860, rue Saint Priest, 34090 \\ Montpellier, France \\ ${ }^{3}$ CRITT-MDTS, 3 bd J. Delautre, 08000 Charleville-Mézières, France \\ ${ }^{4}$ University of Sydney, School of Civil Engineering, NSW 2006 Sydney, Australia \\ *Corresponding author-Tel +33 3257156 68; Fax +33 3257156 75; Email: delphine.retraint@utt.fr
}

\begin{abstract}
The combined effect of superficial nanocrystallisation by SMAT (Surface Mechanical Attrition Treatment) followed by plasma nitriding on the mechanical properties of a medical grade austenitic stainless steel was studied. SMAT conditions were optimised to enhance nitrogen diffusion. Experimental observations (energy dispersive X-ray spectroscopy profiles, cross-sectional optical micrographs, phase analysis by X-ray diffraction and micro-hardness profiles) show that polishing away a very thin layer after SMAT and before nitriding significantly improves nitrogen diffusion into the substrate, yielding a 50\% thicker nitrided layer. Possible causes for this improvement are discussed
\end{abstract}

Keywords: surface diffusion, SMAT, nanocrystalline materials, plasma nitriding, austenitic steels

\section{Introduction}

Austenitic stainless steel AISI 316 - ASTM F138 is a typical medical grade material that is used in many industrial and biomedical applications such as orthopaedic implants, due to its excellent corrosion resistance and biocompatibility. However, its hardness and wear resistance are relatively poor [1]. Many attempts have been made in order to harden its surface [2]. For example, at low temperature nitriding [3], the transformation of austenite into expanded austenite $\left(\gamma_{\mathrm{N}}\right.$, or S-phase) increases the surface hardness while keeping a reasonable corrosion resistance [4]. 
Another process for surface hardening is the Surface Mechanical Attrition Treatment (SMAT) [5]. It generates a nanocrystalline surface layer by severe plastic deformation. This enhances several mechanical properties such as yield and ultimate strengths, but it also decreases the ductility [6]. SMAT has already been combined with other processes such as co-rolling [7], gas nitriding [8, 9] or low-temperature plasma nitriding on AISI 321 steel [10]. In combination with nitriding, SMAT has been shown [8-10] to enhance surface hardness and corrosion resistance. The SMAT increases dislocation density and grain boundary fraction near the surface, thereby providing fast diffusion pathways for the nitrogen atoms into the material. Improved nitrogen diffusivity due to smaller grain size was already observed in AISI 304 steel [11]. Conversely, Cemin et al. [12] studied the influence of another mechanical attrition process, ball milling, on low temperature plasma nitriding of AISI 316 steel, and they demonstrated that ball milling oxidises the metal surface, which blocks the nitrogen flux into the bulk material. Several studies have been performed on similar mechanical surface treatments and materials $[1,2,10]$, however no research has been carried out on the duplex treatment SMAT/nitriding of medical grade austenitic stainless steels.

In this work, a medical grade AISI 316 - ASTM F138 stainless steel is first SMATed and then plasma nitrided. The idea is that SMAT will improve the subsequent nitrogen diffusion, so that a thicker nitrided layer is formed, which would enhance several mechanical properties. Based on the thermal stability TTT diagram of $\gamma_{\mathrm{N}}$ [19], plasma nitriding is carried out for $20 \mathrm{~h}$ at $425^{\circ} \mathrm{C}$ [2]. However, even if the nanostructure generated by SMAT is known to remain stable for at least 10 minutes at $600^{\circ} \mathrm{C}$ [16], no information is available for longer dwell times. Thus, some of the SMATed samples are annealed at $425^{\circ} \mathrm{C}$ for various durations between 5 and $20 \mathrm{~h}$ to study the stability of the nanostructure. The effect of an intermediary polishing step is also investigated. If any oxides would be present, as in [12], this step would remove them. The resulting nitrogen layers obtained with and without polishing are then compared to each other using different techniques (as explained below), as well as to an unSMATed nitrided sample. Finally, the results are discussed and analysed.

\section{Material and methods}

\subsection{Material and surface treatments}

Coupon samples $6 \mathrm{~mm}$ thick were cut from $25 \mathrm{~mm}$ diameter bars. Their chemical composition is given in Tab. 1. Several SMATed samples were annealed (A) in an air furnace at $425^{\circ} \mathrm{C}$ (see Tab. 2). The other samples were subjected to different combinations of SMAT (S), intermediate polishing (P), and nitriding (N), always in that order (see also Tab. 2). In each case two samples were used. During the SMAT, spherical shot is set in motion by a high frequency $(20 \mathrm{kHz})$ ultrasonic generator. Random shot impacts at the sample surface generate severe plastic deformation and a superficial nanocrystalline layer $[5,14]$. This process takes place at standard atmospheric conditions. Suitable SMAT parameters such as processing time $(30 \mathrm{~min})$ and shot size $(3 \mathrm{~mm})$ were chosen based on 
previous experiments [15]. An intermediary polishing step is thus carried out to remove a thin superficial layer of $3 \pm 0.3 \mu \mathrm{m}$. The amount of material removed was measured by successively indenting the surface layer by a Vickers indenter with different loads. Using the projected areas of the indenter, this amount was carefully determined and controlled. Before being placed in the nitriding chamber, the samples were ultrasonically cleaned in an acetone bath. The nitrided samples were all treated in the same manner: they were put into the plasma nitriding furnace simultaneously and at the same distance from the furnace wall. Plasma nitriding was then carried out for $20 \mathrm{~h}$ at $425^{\circ} \mathrm{C} \mathrm{[2]} \mathrm{in} \mathrm{a}$ $20 \% \mathrm{~N}_{2}+80 \% \mathrm{H}_{2}$ gas mixture at a pressure of $500 \mathrm{~Pa}$ [19]. The temperature was measured and controlled by a thermocouple placed inside one of the samples. The nitriding time was chosen according to the thermal stability TTT diagram of $\gamma_{\mathrm{N}}[19]$.

\subsection{Material characterisation}

The materials were characterised by several techniques. Transverse sections were cut for measuring layer thicknesses and grain sizes using Optical and Scanning Electron Microscopy (OM and SEM) as well as Electron BackScattering Diffraction (EBSD). These sections were polished and etched in a 50 vol. $-\% \mathrm{HCl}+25 \% \mathrm{HNO}_{3}+25 \% \mathrm{H}_{2} \mathrm{O}$ solution to reveal the nitrided layer. Microhardness profiles were measured by a Vickers indenter (Model FM-300e) using a $25 \mathrm{~g}$ load. Each data point corresponds to the average of seven indentations. Nitrogen concentration profiles were obtained using a LEO 1450VP SEM with Energy Dispersive X-ray Spectroscopy (EDS). The crystal structure was analysed by X-ray diffraction (XRD) with a Seifert PTS-3000 X-ray diffractometer using $\mathrm{CrK} \alpha$ radiation and Bragg-Brentano conditions, directly on the sample surface.

\section{Results and discussion}

\subsection{Thermal stability of the nanostructure generated by SMAT}

In order to establish the thermal stability of the nanostructure during the nitriding, the grain sizes of different annealed samples (SS, SA5 and SA20) were determined at $2 \mu \mathrm{m}$ below the surface from multiple SEM and EBSD observations. Fig. 1 shows a typical example of one of these microstructures (SS). The average grain sizes are summarised in Tab. 3. It can be observed that the different annealing treatments hardly affect the average grain size of the nanocrystalline surface, and that a nanocrystalline layer composed of nanograins smaller than $50 \mathrm{~nm}$ is still present after $20 \mathrm{~h}$ at $425^{\circ} \mathrm{C}$.

\subsection{Layer morphology and nitrogen profiles}

The thickness of the nitrided layer in each sample was determined by OM (Fig. 2a). Fig. 2a shows that SMAT significantly modifies the thickness and uniformity of the nitrided layer. Samples N425 and SPN425 both have a continuous nitrided layer with relatively uniform thickness, but the one in SPN425 is thicker: $40 \pm 2 \mu \mathrm{m}$ instead of $26 \pm 4 \mu \mathrm{m}$. Conversely, in sample SN425 only a partial nitrided 
layer is present and the thicknesses of its nitride islets are generally smaller than the thicknesses of the nitrided layers of N425 and SPN425.

Average nitrogen profiles along the cross-section of different nitrided samples, obtained by EDS, are shown in Fig. 2b. The net counts presented in this figure are supposed to be proportional to the nitrogen concentration. Three zones of each sample were analysed by EDS to check the accuracy and repeatability of the results. The nitrogen curves fluctuate due to the instrinsic scatter of the measurements. As in the optical micrographs, the nitrogen penetration depths again show that nitrogen diffuses furthest into SPN425 and that it hardly diffuses into SN425.

\subsection{Micro-hardness profile}

In order to have some indication as to how the duplex process affects the hardness, Vickers microhardness (HV) was measured through the cross-sections of the samples as shown in Fig. 3. At the surface, SPN425 and N425 have a similar micro-hardness (1118 \pm 108 and $1088 \pm 110 \mathrm{HV}_{0.025}$ respectively), which is about five times higher than that of the untreated sample. However, the hardness decreases much slower with depth for SPN425 than for N425. This indicates that the nitrided layer of the SPN425 specimen is thicker than the one of the nitrided-only specimen N425. Still further down, after about $60 \mu \mathrm{m}$, the micro-hardnesses of SN425 and SPN425 become similar to the one due to SMAT only, which is still about 1.5 times the value of the untreated and nitrided-only samples.

\subsection{X-ray diffraction}

The samples were also analysed by XRD in the conventional $\theta-2 \theta$ mode (Bragg-Brentano), providing information on phase structure from the nitrided surface layer down to about $5 \mu \mathrm{m}$ below the surface. Fig. 4 shows the results for SS, N425, SN425 and SPN425 as well as for an untreated as-received sample for comparison. The latter yields three major diffraction peaks of $\gamma(111), \gamma(200)$ and $\gamma(220)$ in the $45-145^{\circ}$ range, thus confirming the presence of the austenitic fcc phase. The SMATed sample (SS) gives a similar pattern, without any martensite transformation occurring in the surface layer during SMAT, contrary to [17], where strain-induced martensite transformation was detected. However, this may be due to the different treatment intensity and also a slightly different steel composition. However, all corresponding peaks were slightly broadened and shifted to lower angles, which can be attributed to grain refinement and to a compressive residual stress induced by SMAT [17].

Before any treatment, the AISI 316 stainless steel exhibits a diffraction pattern characteristic of austenite $(\gamma)$. In literature [for instance 1-4, 24], plasma nitriding treatments lead to the formation of a new phase called expanded austenite $\left(\gamma_{N}\right.$, or S-phase), which is a high-N-content solid solution phase. This phase is not included in the ASTM X-ray diffraction index because its lattice parameter strongly 
depends on the nitrogen content. In addition, the phase transformations in stainless steel after low temperature plasma nitriding depend on all process parameters [25] such as process temperature, nitrogen implantation dose rate, nitrogen ion energy, processing time, etc. Thus, with increasing temperature or nitriding time, the $\gamma_{\mathrm{N}}$ phase further transforms into other nitrogen-containing phases, for instance iron nitrides $\gamma^{\prime}-\mathrm{Fe}_{4} \mathrm{~N}$ or $\varepsilon-\mathrm{Fe}_{2-3} \mathrm{~N}$, chromium nitrides $\mathrm{CrN}$ and $\mathrm{Cr}_{2} \mathrm{~N}$, or a martensitic/ferritic phase [22, 24, 25, 26, 27], and it not always clear exactly which phases are present.

For instance, in our case the highest peak in the SN425 pattern may contain $\gamma$-austenite (111), $\alpha$ martensite (101), and $\mathrm{CrN}$ (200), but their relative contributions cannot be established or distinguished for that peak. Also, the peak just next to it can be either $\alpha^{\prime}$-martensite (110) and/or $\alpha$-ferrite (110). The same goes for the very low $\alpha / \alpha^{\prime}$ (200) peaks which may or may not be present or confounded with the adjacent $\mathrm{CrN}$ (220) peak. Thus, from this measurement alone the presence of $\alpha$ '-martensite or $\alpha$ ferrite cannot be established. A similar discussion can be found in [27] but the precise identification is out of the scope of the present paper. Also it is not clear why one or both of these phases appear for SN425 but not for N425 or SPN425, and neither SMAT nor nitriding alone induces the formation of these phases. The presence of $\mathrm{CrN}$ is discussed later on.

The $\gamma_{\mathrm{N}}$ phase can be observed in the patterns of N425 and SPN425. The peaks induced by plasma nitriding for N425 and SPN425 appear at lower Bragg angles than the peaks of the original austenite, indicating the formation of two phases $\left(\gamma_{\mathrm{N}}\right.$ and $\left.\gamma^{\prime}-\mathrm{Fe}_{4} \mathrm{~N}\right)$. Those corresponding to the $\gamma$ phase disappear, so the $\gamma$ phase is completely transformed down to $5 \mu \mathrm{m}$ depth

One interesting feature in Fig. 4 is the slightly higher relative intensity of $\gamma_{\mathrm{N}}$ peaks for SPN425 with respect to N425. This may be related to the enhancement of the formation of $\gamma_{N}$ due to the faster nitrogen diffusion because of the high dislocation density together with the small grain size induced by SMAT. However, the Bragg peaks of sample SN425 showed that the three peaks of austenite remain, so the austenite does not transform completely into $\gamma_{\mathrm{N}}$ here. Furthermore, the $\gamma_{\mathrm{N}}$ peaks for SN425 are lower than those in SPN425 and N425, which means that less of this hard phase is present. This is consistent with the micrographic observations and may explain the greater hardening in these two samples at the surface (SPN425 and N425).

Surprisingly, the XRD analysis also shows that $\mathrm{CrN}$ is present in the nitrided samples (N425, SPN425 and SN425), whereas according to the thermal stability diagrams of S-phase proposed in [19], a precipitation-free layer should be formed after a $20 \mathrm{~h}$ nitriding treatment at $425^{\circ} \mathrm{C}$. However, this might be explained by the slightly different chemical composition of the stainless steel studied here. Nevertheless, the amount of $\mathrm{CrN}$ does not appear to be significant because of the low intensity of the 
peaks, which is consistent with [20]. Moreover, in the SPN425 sample a 60-120 nm thick passivating layer was observed with SEM, thereby confirming that there is no significant depletion of $\mathrm{Cr}$, which would hinder its formation [21].

The nitrogen concentration and microhardness profiles as well as the metallographical and compositional analyses in the present work confirm that the duplex treatment is sensitive to the surface preparation before plasma nitriding. In other words, at lower nitriding temperatures, the penetration of nitrogen into the SMATed sample was diminished with respect to the nitrided-only samples. This is thought to be due to surface oxides that act as a barrier for nitrogen incorporation, as was observed in the literature for ball milling [12]. Similar oxides were observed in [13], where titanium residues from the sonotrode were deposited at the surface, which were oxidised subsequently. However, in the present work the oxides were removed by the polishing step while preserving the superficial nanocrystalline structure induced by SMAT. The fraction of grain boundaries, which act as fast atomic diffusion channels of nitrogen, was thus increased. As a result, the thickness of the nitrided layer increased by about $50 \%$ for SPN425 with respect to N425. This demonstrates the importance of the polishing step and supports the idea that surface oxides may block the nitrogen diffusion into the SMATed samples.

It should be noted that in [10], an intermediary polishing step was also carried out. However, in that case the reason was to eliminate the effect of surface roughness induced by SMAT on the tribological behaviour. Finally, other parameters might also play a role, such as the residual stresses and, indeed, the surface roughness. Further experiments are currently under way in order to evaluate their influence.

\section{Conclusion}

SMAT and nitriding were combined into a duplex process in order to increase the thickness of the nitrided layer, thereby improving the hardness profile near the sample surfaces of a medical-grade austenitic stainless steel AISI 316 - ASTM F138. First, SEM observations coupled with EBSD were carried out in order to establish whether the superficial nanostructure induced by SMAT remained stable under subsequent nitriding conditions. It was demonstrated that a nanocrystalline layer composed of nanograins smaller than $50 \mathrm{~nm}$ was still present after $20 \mathrm{~h}$ at $425^{\circ} \mathrm{C}$. Second, the samples were SMATed and then nitrided. With respect to samples that were nitrided only, preliminary SMAT decreased the hardness and diminished the thickness and the homogeneity of the nitrided layer. This is thought to be due to surface oxides that block nitrogen diffusion. Thus, an additional polishing step was carried out between SMAT and nitriding in order to remove the barrier oxide. With respect to samples that were nitrided only, the thickness of the nitrided layer increased by about $50 \%$ from $26 \pm 4$ 
$\mu \mathrm{m}$ to $40 \pm 2 \mu \mathrm{m}$. Moreover, despite the formation of small quantities of $\mathrm{CrN}$, a continuous passivating layer of chromium oxide was observed at the top surface of this sample.

Further analyses are currently under way to confirm the presence of the surface oxides. Also, additional experiments are being carried out in order to understand the interaction between the polishing step, the surface roughness, the residual stresses, and the subsequent nitriding.

\section{Acknowledgements}

The authors gratefully acknowledge financial support from the Regional Council of ChampagneArdenne (France) through the NANOSURF project as well as from the European FEDER programme.

They also acknowledge the technical assistance of Dr H. Liu and L. Aschehoug of the Australian Microscopy \& Microanalysis Research Facility at the Australian Centre for Microscopy and Microanalysis, University of Sydney.

\section{References}

[1] H. Dong, Int. Mat. Rev. 55(2) (2010) 65-98.

[2] J. Buhagiar, H. Dong, T. Bell, Surf. Eng. 23 (2007) 313-317.

[3] Z.L Zhang, T. Bell, Surf. Eng. 1(2) (1985) 131-136.

[4] C.X. Li, T. Bell, Corros. Sci. 46 (2004) 1527-1547.

[5] K. Lu, J. Lu, Mat. Sci. Eng. A375-377 (2004) 38-45.

[6] D. Retraint, Mat. Te 99 (2011) 101-104.

[7] L. Waltz, D. Retraint, A. Roos, P. Olier, Scr. Mat. 60 (2009) 21-24.

[8] W.P. Tong, C.Z. Liu, W. Wang, N.R. Tao, Z.B. Wang, L. Zuo, J.C. Hea, Scr. Mat. 57 (2007) 533536.

[9] W.P. Tong, Z. Han, L.M. Wang, J. Lu, K. Lu, Surf. Coat. Tech. 202 (2008) 4957-4963.

[10] Y. Lin, J. Lu, L. Wang, T. Xu and Q. Xue, Acta Mat. 54 (2006) 5599-5605.

[11] D. Manova, S. Mändl, H. Neumann, Surf. Coat. Tech. 201 (2007) 6686-6689.

[12] F. Cemin, F.G. Echeverrigaray, A.C. Rovani, C.L.G. Amorim, R.L.O. Basso, I.J.R. Baumvol, C.A. Figueroa, Mat. Sci. Eng. A527 (2010) 3206-3209.

[13] L. Waltz, D. Retraint, A. Roos, C. Garnier, P. Olier, Surf. Coat. Tech. 205 (2011) 4608-4613.

[14] D. Retraint. C. Pilé, C. Garnier, J. Lu, 2nd Edition, Ed. Society for Experimental Mechanics, Vol.1 (2005) 146-159.

[15] M. Chemkhi, D. Retraint, G. Montay, C. Garnier, F. Belahcene, International conference on shot peening, N 11, South Bend, Indiana, USA, (2011).

[16] T. Roland, D. Retraint, K. Lu, J. Lu, Mat. Sci. Eng. A445-446 (2007) 281-288. 
[17] T. Roland, D. Retraint, K. Lu, J. Lu, Scr. Mat. 54 (2006) 1949-1954.

[18] W. Li, X. Li, H. Dong, Acta Mat. 59 (2011) 5765-5774.

[19] T. Bell, Surf. Eng. 18 (6) (2002) 415-422.

[20] S. Mändl, R. Günzel, E. Richter, W. Möller, Surf. Coat. Tech. 100-101 (1998) 372-376.

[21] A. Triwiyanto, S. Mridha, E. Haruman, Adv. Mater. Res. 83-86 (2010) 489-496.

[22] Y. Sun, X. Y. Li, T. Bell, J. Mater. Sci. 34 (1999) 4793-4802.

[23] T. Christiansen, M. A. J. Somers, Revue de Matérialographie Struers (2006).

[24] M. K. Lei, Y. Huang and Z. L. Zhang, J. Mater. Sci. Lett. 17 (1998) 1165-1167.

[25] M. K. Lei, Mater. Sci. 34 (1999) 5975-5982

[26] S.-P. Hannula, P. Nenonen, J.-P. Hirvonen, Thin Solid Films 181 (1989) 343-350.

[27] C. Blawert, B.L. Mordike, Y. Jirásková , O. Schneeweiss, Surf. Coat. Tech 116-119 (1999) 189198. 


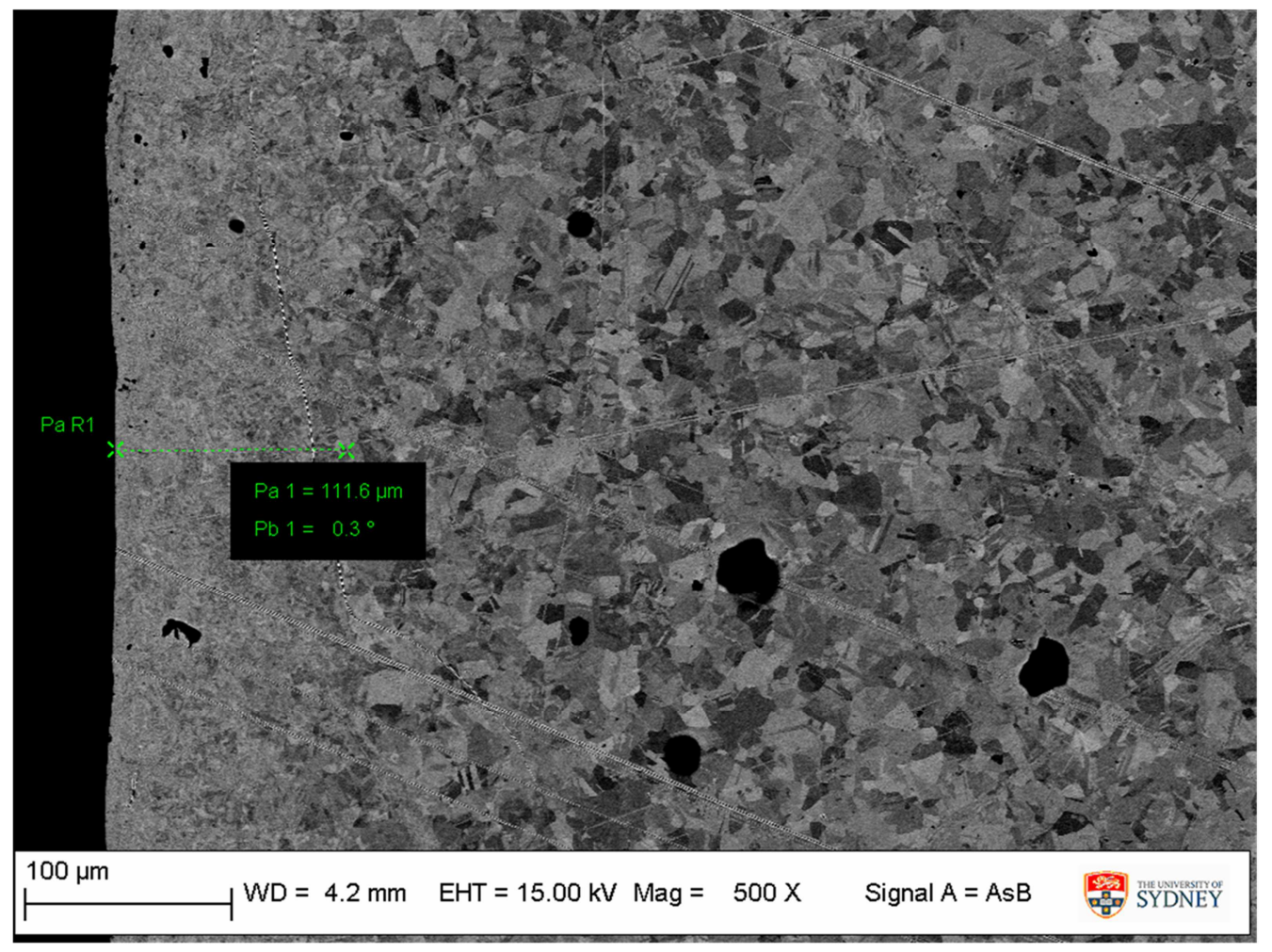

Fig. 1. Cross-sectional SEM micrograph of the SMATed sample (SS). 

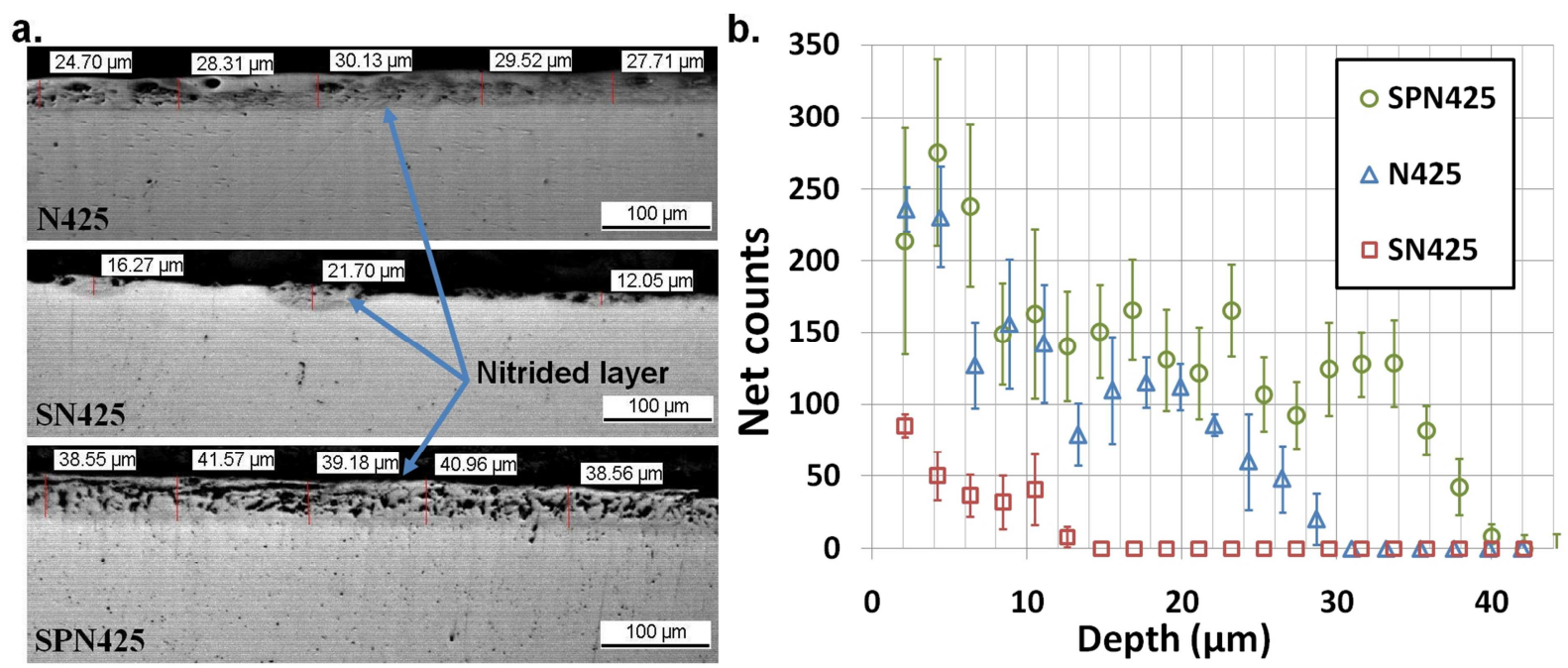

Fig. 2. a. Cross-sectional optical micrographs of samples N425, SN425 and SPN425. The thickness of each nitrided layer is measured at different locations and some of them are indicated there, and $\mathbf{b}$. EDS nitrogen concentration profiles for different sample treatments. 


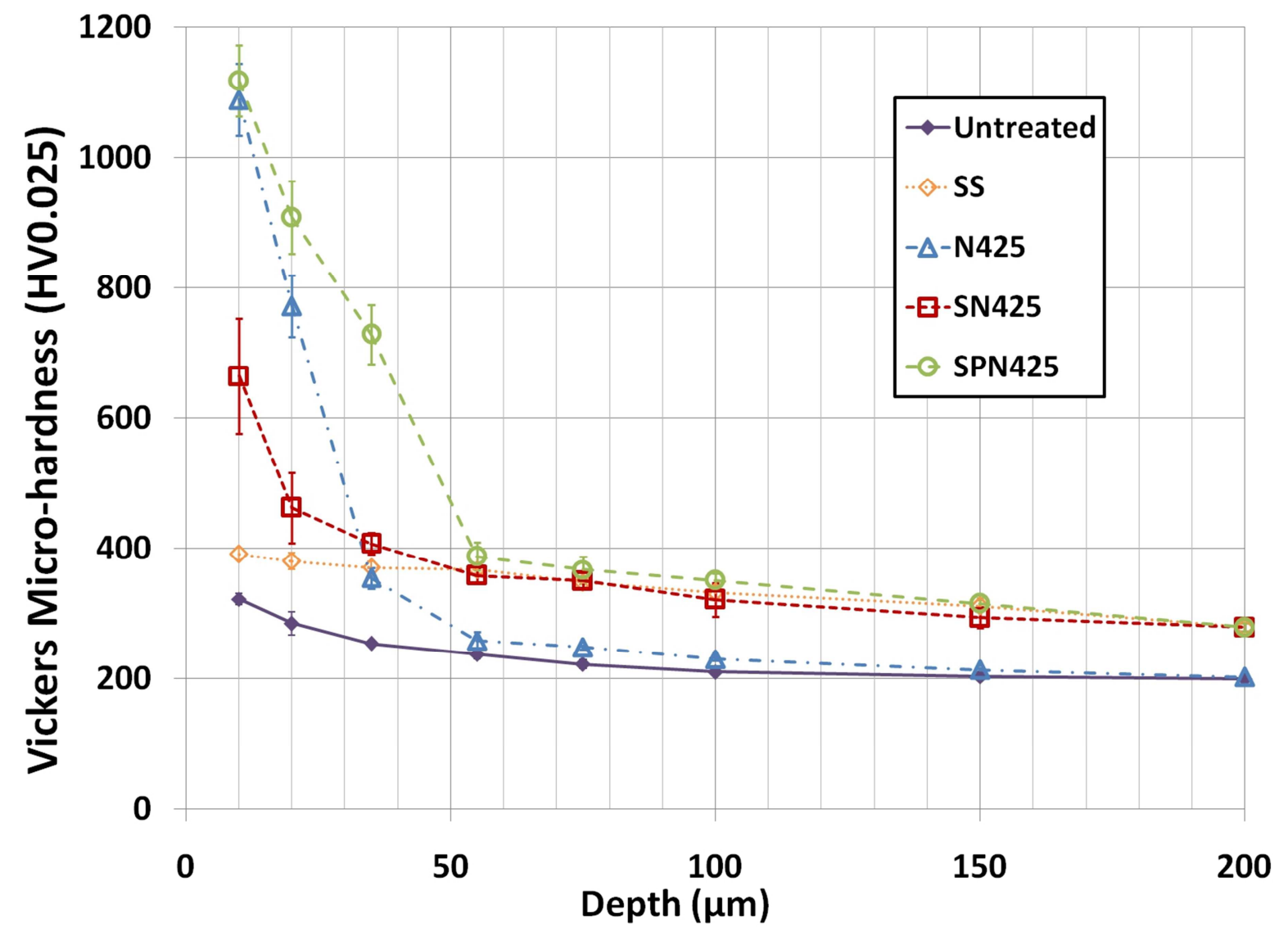

Fig.3. Average cross-sectional Vickers micro-hardness profiles. 


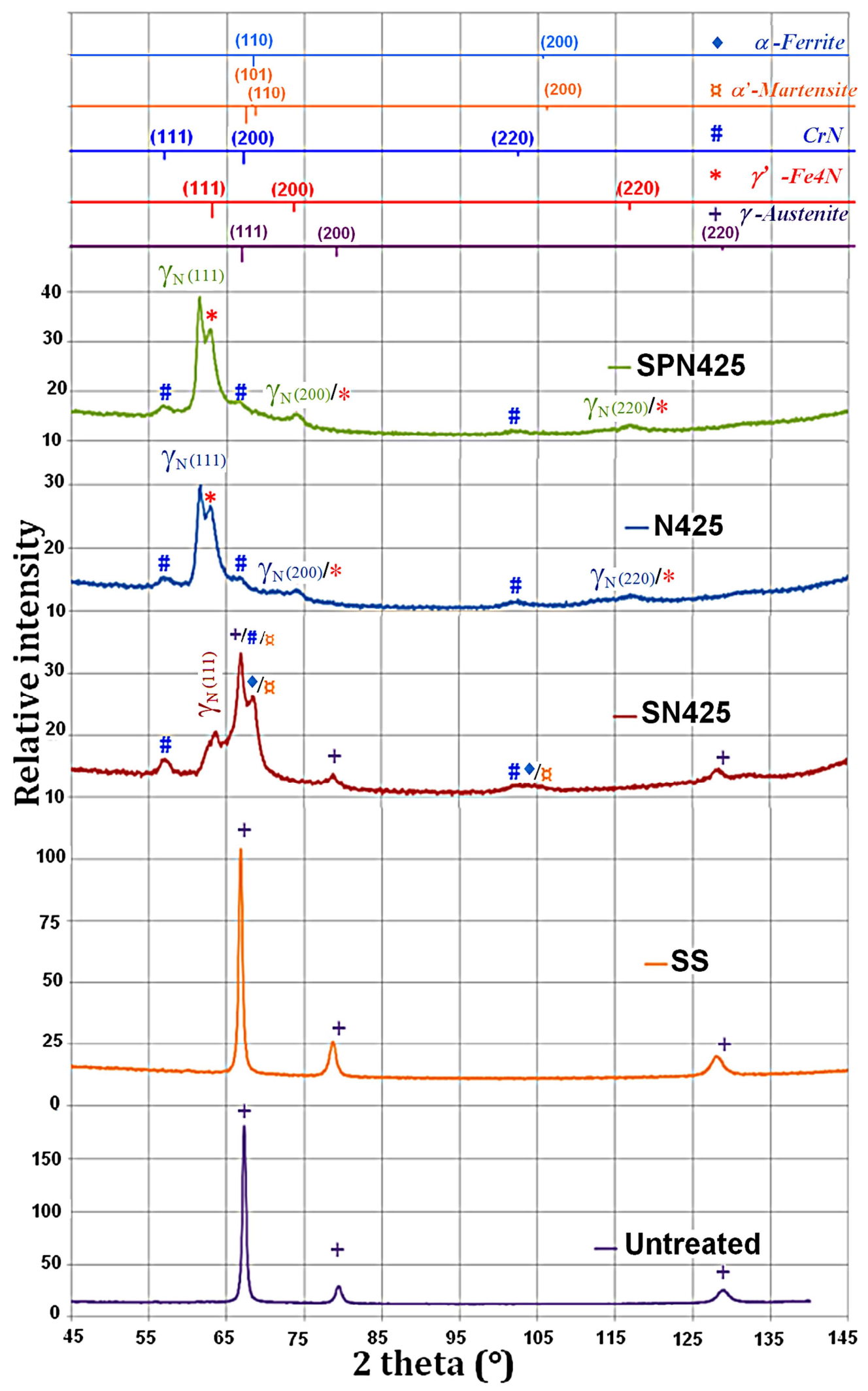

Fig. 4. X-ray diffraction patterns obtained for different sample treatments. For each phase, the locations of the peaks, according to standard ASTM patterns, are marked on the horizontal lines at the top of the figure. The length of each tick mark there corresponds to the relative intensity of each peak for that phase. 


\begin{tabular}{|c|c|c|c|c|c|c|c|c|c|c|c|c|c|}
\hline Element & $\mathbf{F e}$ & $\mathbf{C}$ & $\mathbf{M n}$ & $\mathbf{S i}$ & $\mathbf{P}$ & $\mathbf{S}$ & $\mathbf{C r}$ & $\mathbf{N i}$ & $\mathbf{M o}$ & $\mathbf{C u}$ & $\mathbf{N}$ & $\mathbf{T i}$ & $\mathbf{V}$ \\
\hline Weight \% & 48,4 & 0.013 & 1.7 & 0.26 & 0.017 & 0.003 & 17.37 & 14.52 & 2.80 & 0.08 & 0.088 & $<0.005$ & 0.07 \\
\hline
\end{tabular}

Table 1. Composition (wt. \%) of the as-received austenitic stainless steel AISI 316 - ASTM F138. 


\begin{tabular}{|c|c|c|c|c|}
\hline Designation & SMAT & Annealing & Polishing & Nitriding \\
\hline Untreated & - & - & - & - \\
SA5 & $\checkmark$ & $5 \mathrm{~h}$ & - & - \\
SA20 & $\checkmark$ & $20 \mathrm{~h}$ & - & - \\
SS & $\checkmark$ & - & - & - \\
N425 & - & - & - & $20 \mathrm{~h}$ at $425^{\circ} \mathrm{C}$ \\
SN425 & $\checkmark$ & - & - & $20 \mathrm{~h}$ at $425^{\circ} \mathrm{C}$ \\
SPN425 & $\checkmark$ & - & $\checkmark$ & $20 \mathrm{~h}$ at $425^{\circ} \mathrm{C}$ \\
\hline
\end{tabular}

Table 2. Sample treatments. 


\begin{tabular}{|c|c|}
\hline Sample & Average Grain Size (nm) \\
\hline SS & $47 \pm 29$ \\
SA5 & $42 \pm 27$ \\
SA20 & $42 \pm 26$ \\
\hline
\end{tabular}

Table 3. Average grain size at $2 \pm 1 \mu \mathrm{m}$ below the surface for different treatments. 